\title{
ETNOMATEMATIKA PADA PEMBUATAN BATIK DI PERUSAHAAN TATSAKA CLURING BANYUWANGI SEBAGAI LEMBAR KERJA SISWA
}

\author{
Yuli Farida ${ }^{1}$, Susanto ${ }^{2}$, Toto' Bara Setiawan ${ }^{2}$ \\ Program Studi Pendidikan Matematika, FKIP, Universitas Jember \\ Jalan Kalimantan 37 Kampus Tegalboto Jember 68121 \\ E-mail: yulifarida794@gmail.com
}

\begin{abstract}
Ethnomatematics is a science used to understand how mathematics is adapted from a culture. The purpose of this study is to dig ethnomatematics on the making of batik tulis Kangkung Setingkes and create a student worksheet in accordance with the curriculum 2013. This type of research is qualitative with ethnographic approaches. The subject in this study amounted to seven people. Data Collection using observation methods, interviews, and documentation. Data collection results are analyzed descriptively. Based on the analysis of data from the observation and interviews, obtained ethnomatematics in the process of making batik in the Setingkes Kangkung. The meaning of Ethnomatematics is the concept of algebraic and geometric concepts. Algebraic concepts include counting, measuring, and masing and geometry concepts, such as point, line, angle, construction, congruation, and Geometry transformation (translation, rotation, reflection, dilation). Ethnomatematics in this study were made as student worksheets for class VII of comparative material and the XI class of geometry transformation material.
\end{abstract}

Keyword : Ethnomatematics, Batik, Student worksheets

\section{PENDAHULUAN}

Matematika sebagai alat komunikasi (mathematics is a connection) diperlukan baik oleh semua ilmu pengetahuan maupun dalam kehidupan seharihari [1]. Salah satu materi yang sangat erat kaitannya dengan kehidupan seharihari yaitu geometri. Geometri merupakan salah satu materi pelajaran yang selalu ada pada jenjang pendidikan dari sekolah dasar sampai perguruan tinggi. Di sekolah dasar utamanya, pembelajaran tentang konsep geometri telah dikenalkan kepada siswa kelas rendah. Oleh karena itu untuk menjadikan materi geometri ini lebih menarik, dibutuhkan suatu metode belajar yang berkaitan dengan budaya

\footnotetext{
${ }^{1}$ Mahasiswa S1 Prodi Pendidikan Matematika FKIP Universitas Jember

${ }^{2}$ Dosen Prodi Pendidikan Matematika FKIP Universitas Jember
} 
yang sering dijumpai. Metode belajar yang mengaitkan unsur budaya dengan matematika ini disebut dengan etnomatematika [2].

Etnomatematika adalah suatu pendekatan yang mengaitkan antara matematika dengan konsep-konsep kebudayaan tertentu yang di dalamnya mencakup aktivitas-aktivitas matematika yang digambarkan pada konteks budaya [3]. Etnomatematika dalam pendidikan juga sangat berperan dalam pembelajaran, hal ini dikarenakan banyak siswa yang membutuhkan pengajaran yang lebih menarik agar matematika yang dianggap sukar oleh siswa bisa lebih mudah untuk dipahami [4]. Pembelajaran bermuatan pembelajaran matematika realistik berbasis etnomatematika dirasa akan memberikan motivasi belajar serta pemahaman konsep suatu materi oleh siswa menjadi lebih mudah karena materi tersebut terkait langsung dengan budaya mereka, yang merupakan aktivitas mereka sehari-hari dalam bermasyarakat [5].

Matematika dan budaya memiliki kaitan yang sangat erat dengan kehidupan masyarakat, namun sering kali masyarakat tidak menyadari bahwa mereka telah menerapkan berbagai konsep matematika dalam adat istiadat dan budaya mereka. Pentingnya memadukan antara matematika dan budaya, yaitu untuk menekankan rasa cinta produk dalam negeri yang sudah menjadi identitas bangsa agar tidak hilang dan dapat digunakan sebagai contoh penerapan materi matematika dalam kehidupan sehari-hari. Salah satu budaya yang ada di masyarakat adalah batik [6]. Batik adalah suatu cara penerapan corak di atas kain melalui proses celup rintang warna dengan malam sebagai medium perintangnya [7].

Motif batik Kangkung Setingkes adalah salah satu motif batik khas Banyuwangi. Seiring waktu berjalan, kini motif batik Kangkung Setingkes sudah berkembang dan menjadi kegemaran masyarakat Banyuwangi. Kegunaan motif batik Kangkung Setingkes antara lain sebagai busana, sembong Bali, udeng, sepatu, dan kemeja. Oleh karena itu, batik Kangkung Setingkes dapat dijadikan sebagai salah satu media pembelajaran matematika berbasis etnomatematika. Proses pembuatan batik, jika dihubungkan dengan matematika memuat aktivitas menghitung, mengukur, dan membilang sedangkan pada motif batik Kangkung Setingkes, jika dihubungkan dengan matematika merupakan salah satu motif yang 
berbentuk geometris. Unsur geometri pada motif batik Kangkung Setingkes berupa titik, garis, sudut, kesebangunan, kekongruenan, dan transformasi geometri. Satu unsur pada motif batik Kangkung Setingkes dapat disusun berdasarkan konsep transformasi geometri yaitu translasi, rotasi, dilatasi, dan refleksi. Proses perlakuan tersebut dapat dilakukan dengan berbagai cara dan urutan transformasi tertentu. Konsep matematika yang termuat pada batik Kangkung Setingkes dijadikan sebagai Lembar Kerja Siswa (LKS).

LKS adalah bahan ajar yang sudah dikemas sedemikian rupa berupa lembaran-lembaran yang berisi soal-soal yang harus dikerjakan siswa sebagai sarana untuk menjadikan siswa dapat berpikir aktif dan dapat belajar mandiri [8]. Melalui LKS siswa dibimbing untuk memecahkan persoalan yang diberikan dengan tujuan siswa mampu membangun atau mengkonstruksi sendiri pengetahuannya [9]. Dengan demikian, LKS bermanfaat sebagai salah satu alternatif bahan ajar yang dapat mengaktifkan siswa dalam pembelajaran untuk menemukan dan mengembangkan konsep sehingga dapat memfasilitasi kemampuan matematis siswa [10].

Berdasarkan pemaparan di atas peneliti ingin mengetahui lebih jelas tentang etnomatematika pada pembuatan batik khususnya motif Kangkung Setingkes. Tujuan penelitian ini adalah menemukan adanya unsur-unsur matematika pada pembuatan batik serta menghasilkan Lembar Kerja Siswa (LKS) yang sesuai dengan kurikulum 2013 materi perbandingan untuk kelas VII dan materi transformasi geometri untuk kelas XI.

\section{METODE PENELITIAN}

Jenis penelitian ini adalah kualitatif dengan pendekatan etnografi. Penelitian ini dilakukan di Perusahaan Tatsaka Cluring Banyuwangi. Penelitian ini difokuskan pada proses pembuatan batik serta hasil batik tulis Kangkung Setingkes. Pengumpulan data menggunakan metode observasi, wawancara, dan dokumentasi. Subjek dalam penelitian ini adalah 7 karyawan di Perusahaan Batik Tatsaka.

Langkah pertama dalam penelitian ini adalah pemilihan tempat dan subjek 
penelitian. Langkah kedua adalah pembuatan instrumen penelitian berupa pedoman observasi dan pedoman wawancara. Instrumen penelitian tersebut kemudian divalidasi oleh validator. Langkah ketiga adalah pengumpulan data, pada penelitian ini pengumpulan data diperoleh dari metode observasi, wawancara, dan dokumentasi. Observasi pada penelitian ini dilakukan dengan cara mengamati secara langsung aktivitas karyawan perusahaan yang berkaitan dengan aktivitas membatik. Wawancara dilakukan untuk memperoleh data yang lebih mendalam mengenai proses pembuatan batik. Dokumentasi merupakan data pendukung yang dilakukan sebelum dan sesudah wawancara. Langkah keempat yaitu analisis data, langkah ini dilakukan dengan menyusun data sesuai dengan fokus kajian masalah dan tujuan penelitian. Langkah kelima yaitu pembuatan Lembar Kerja Siswa (LKS) mengenai bab perbandingan dan transformasi geometri. Langkah keenam yaitu kesimpulan, peneliti membuat kesimpulan dari hasil analisis data yang telah diperoleh.

\section{HASIL DAN PEMBAHASAN}

Berdasarkan analisis data dari hasil observasi dan wawancara, etnomatematika yang diamati pada proses pembuatan batik serta hasil batik Kangkung Setingkes antara lain menghitung banyaknya motif pada satu lembar kain, menghitung kebutuhan malam, menghitung perbandingan pewarna, menghitung kebutuhan waterglass, mengukur kebutuhan air pada proses "nglorod", menyebutkan jumlah bilangan dan satuan untuk alat dan bahan

membatik, menemukan titik pada batik Kangkung Setingkes, menemukan garis pada batik Kangkung Setingkes, menemukan konsep sudut pada batik Kangkung Setingkes, menemukan konsep kesebangunan dan kekongruenan pada batik Kangkung Setingkes, menemukan konsep transformasi geometri pada batik Kangkung Setingkes.

Etnomatematika yang diamati pada proses pembuatan batik antara lain sebagai berikut.

\section{Menghitung Banyaknya Motif pada Satu Lembar Kain}

Pertanyaan dan jawaban N2 dalam menentukan banyaknya motif pada satu 
lembar kain sebagai berikut.

P:2005 : Mbak, saya perhatikan pada batik Kangkung Setingkes ini kenapa motifnya hanya empat?

N:2005 : Untuk batik tulisnya ukurannya mengikuti pola pada batik cap mbak. Disini batik cap Kangkung Setingkes ukurannya kebesaran, jadi untuk jenis lainnya ukurannya juga besar makanya itu kainnya ini hanya memuat empat motif Kangkung Setingkes berukuran besar.

P:2013 : Dalam satu helai kain terdapat berapa banyak motif?

N:2013 : Tergantung mau motif apa, seandainya motif Gajah Oling bisa digabungkan dengan motif Kangkung Setingkes atau dengan motif Bunga Besar juga bisa. Dalam satu kain bisa 2 sampai 3 motif.

Kangkung Setingkes yang sudah digambarkan dikain berjumlah 4 pola dengan ketentuan jaraknya sama. Penentuan jarak ini terbagi menjadi 4 bagian diantaranya bagian punggung, bagian badan depan, dan kedua lengan. Oleh karena itu perhitungan gambar batik tulis Kangkung Setingkes adalah $4 \times 1=4$. Berdasarkan hal tersebut, maka etnomatematika yang terdapat pada aktivitas menentukan banyak motif untuk satu lembar kain adalah operasi hitung.

\section{Menghitung Kebutuhan Malam}

Pertanyaan dan jawaban N1 selaku karyawan bagian pemasaran, dalam menentukan banyaknya kebutuhan malam sebagai berikut.

P:1016 : Bagaimana cara Mbak menghitung kebutuhan malam untuk proses mencanting?

N:1016 : Untuk mencanting kurang lebih butuh satu ons malam mbak, nanti kalau kurang ya di isi lagi tapi kalau warnanya sudah pekat itu sebaiknya diganti. Kalau banyaknya malam itu dipengaruhi sama kebutuhan, kebutuhan motif yang akan dicanting mbak.

\section{Menghitung Perbandingan Pewarna}

Proses pewarnaan batik terbagi menjadi 2 macam yaitu teknik celup dan teknik colet. Menurut N3 selaku karyawan bagian pewarnaan (teknik celup), pewarnaan dengan teknik celup membutuhkan banyak pewarna hal ini berbeda dengan teknik colet, pewarnaan dengan teknik colet tidak membutuhkan banyak pewarna. Berdasarkan hal tersebut, etnomatematika yang terdapat pada aktivitas menghitung kebutuhan pewarna adalah operasi hitung dan perbandingan senilai.

Pertanyaan dan jawaban N3 selaku karyawan bagian pewarnaan (teknik celup), dalam menentukan banyaknya pewarna sebagai berikut. 
P:3004 : Untuk satu helai kain, bagaimana menghitung kebutuhan pewarnanya?

$\mathrm{N}: 3004$ : 1 liter pewarna ditambah air secukupnya untuk 3 potong kain.

Pertanyaan dan jawaban N4 selaku karyawan bagian pewarnaan (teknik colet), dalam menentukan waktu yang dibutuhkan untuk proses pewarnaan batik sebagai berikut.

P:4004 : Berapa lama waktu yang dibutuhkan untuk mencolet?

N:4004 : Tergantung motif mbak, kalau sulit bisa selesai dalam waktu 15 menit kalau yang sederhana cuma 5 menit.

\section{Menghitung Kebutuhan Waterglass}

Penggunaan waterglass dan air menyesuaikan kebutuhan, apabila kain yang akan diproduksi banyak maka pencampuran waterglass dan air juga semakin banyak. Berdasarkan hal tersebut, maka etnomatematika yang terdapat pada aktivitas menentukan banyaknya kebutuhan waterglass adalah operasi hitung dan perbandingan senilai. Pertanyaan dan jawaban N5 selaku karyawan bagian pemberian waterglass, dalam menentukan banyaknya kebutuhan waterglass sebagai berikut.

P:5002 : Untuk perbandingan waterglass sama airnya berapa?

N:5002 : $3: 1$ mbak, 3 liter waterglass 1 liter air.

P:5003 : Perbandingan 3:1 untuk berapa kain Mas?

N:5003 : Secukupnya. Menyesuaikan kalau kurang ya ditambahi lagi.

\section{Mengukur Kebutuhan Air Pada Proses "Nglorod"}

Pertanyaan dan jawaban N6 selaku karyawan bagian penglorodan kain dan perendaman kain, mengenai aktivitas mengukur kebutuhan air pada proses penglorodan sebagai berikut.

P:6005 : Bagaimana cara mengukur kebutuhan air pada proses penglorodan?

N:6005 : Tergantung banyaknya kain, kalau banyak pakai tong itu yang sudah di isi air. Tapi jangan sampai penuh biar nggak tumpah saat kain dimasukkan. Kalau jumlahnya sedikit pake panci saja cukup. Airnya separuh panci aja cukup mbak.

\section{Menyebutkan jumlah bilangan dan satuan untuk alat dan bahan membatik}

Berdasarkan analisis data, aktivitas membilang berkaitan dengan penyebutan satu toples, satu gayung, lima belas menit, dan tiga jam. Satuan yang sering digunakan adalah centimeter $(\mathrm{cm})$, meter (m), liter (1), yard, ons (hg), dan 
gram (gr). Meter digunakan untuk menghitung panjang kain yang telah dipotong. Satuan yard digunakan untuk menghitung panjang kain, liter digunakan untuk menyatakan volume, gram digunakan untuk menyatakan berat pewarna yang akan dicairkan, centimeter digunakan untuk satuan garis tepi dan ons digunakan sebagai satuan berat malam.

\section{Menemukan titik pada batik Kangkung Setingkes}

Titik diberikan sebagai isian pada bagian daun dan bunga. Pembatik menorehkan isian berupa titik-titik dengan tujuan untuk memenuhi ornamenornamen yang kosong. Jumlah titik yang dihasilkan tidak sama dan ukurannya pun beragam ada yang besar dan adapula yang kecil. Berdasarkan hal tersebut, etnomatematika pada batik tulis Kangkung Setingkes adalah titik. Hasil observasi oleh P terkait titik disajikan pada Tabel 1 berikut.

Tabel 1. Hasil Observasi Terkait Titik pada Batik Kangkung Setingkes

\begin{tabular}{lll}
\hline \multicolumn{1}{c}{ Indikator } & Aspek & \multicolumn{1}{c}{ Catatan } \\
\hline $\begin{array}{l}\text { Mengamati } \\
\text { pola titik pada }\end{array}$ & Titik & Titik terdapat pada ornamen \\
batik & batik Kangkung Setingkes \\
Kangkung & seperti yang ditunjuk oleh \\
petingkes & yanah (a) memiliki ukuran & Dokumentasi \\
& berukuran besar ada pula \\
& yang kecil. Titik diberikan \\
& dengan tujuan untuk \\
& memenuhi ornamen yang \\
& kosong.Titik tidak memiliki \\
& jumlah yang sama pada \\
& setiap pola.
\end{tabular}

Pertanyaan dan jawaban narasumber mengenai aktivitas pembuatan pola titik sebagai berikut.

P:7016 : Kalau yang seperti ini mbak di batik Kangkung Setingkes, ini kan ada panah (a) pada (Tabel 1) ini namanya apa mbak?

N:7016 : Ini mbak (sambil menunjuk panah (a)). Ini Namanya titik atau biasa disebut isian mbak.

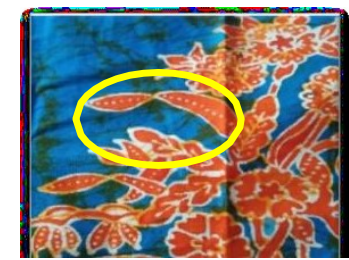

Gambar 1. Ilustrasi Titik 


\section{Menemukan garis pada batik Kangkung Setingkes}

Berdasarkan hasil penelitian, terdapat garis lurus yang diberikan sebagai ornamen pada batang batik Kangkung Setingkes sedangkan garis lengkung diberikan sebagai ornamen pada daun yang terlihat memanjang ke bawah, perbedaan ini menunjukkan adanya keberagaman pola. Berdasarkan hal tersebut etnomatematika yang terdapat pada bagian batang batik Kangkung Setingkes adalah garis. Hasil observasi oleh $\mathrm{P}$ terkait garis disajikan pada Tabel 2 berikut.

Tabel 2. Hasil Observasi Terkait Garis pada Batik Kangkung Setingkes

\begin{tabular}{|c|c|c|c|}
\hline Indikator & Aspek & Catatan & Dokumentasi \\
\hline $\begin{array}{l}\text { Mengamati } \\
\text { pola garis } \\
\text { pada batik } \\
\text { Kangkung } \\
\text { Setingkes }\end{array}$ & Garis & $\begin{array}{l}\text { Terdapat garis yang } \\
\text { berfungsi sebagai batang } \\
\text { seperti yang ditunjuk oleh } \\
\text { panah (c) dan tulang daun } \\
\text { oleh panah (b). Garis pada } \\
\text { tulang daun tergolong isian } \\
\text { (isen-isen) yang berfungsi } \\
\text { untuk memperjelas bentuk } \\
\text { daun dan memperindah } \\
\text { ornamen-ornamen yang } \\
\text { kosong. }\end{array}$ & \\
\hline
\end{tabular}

Pertanyaan dan jawaban narasumber mengenai aktivitas pembuatan pola garis sebagai berikut.

P:7021 : Kalau yang seperti ini Bu di batik Kangkung Setingkes, ini kan ada gambar panah (c) ini namanya apa Bu?

$\mathrm{N}: 7021$ : Itu bagian batangnya mbak, garis-garis gitu.

P:7022 : Bagaimana cara Ibu membuat pola garis pada batik Kangkung Setingkes seperti yang ditunjuk oleh panah (c)?

N:7022 : Awalnya ya digambar mbak dikertas hvs, terus diblat kan ke kain baru pencantingan ngikuti pola yang sudah digambar mbak.

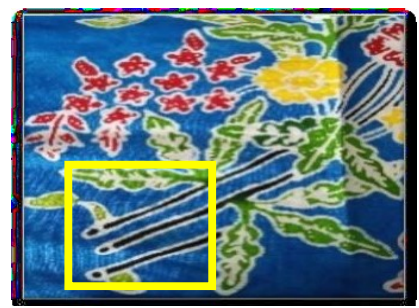

Gambar 2. Ilustrasi Garis 


\section{Menemukan Konsep Sudut pada Batik Kangkung Setingkes}

Bentuk sudut pada motif Kangkung Setingkes nampak pada bagian tulang daun seperti (Gambar 3) terdapat garis lurus yang memanjang kemudian ada dua garis di bagian kanan dan kiri yang bertemu pada satu titik pangkal yang sama.
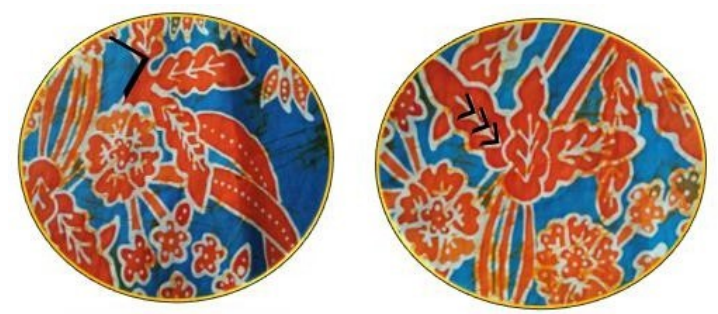

Gambar 3. Ilustrasi Sudut

Berdasarkan hal tersebut, etnomatematika yang terdapat pada bagian ornamen daun adalah konsep sudut. Pertanyaan dan jawaban narasumber mengenai aktivitas pembuatan pola sudut sebagai berikut.

P:7029 : Garis-garis itu harus bertemu dititik tengah ini ya Bu?

N:7029 : Iya mbak, karena itu kan menggambarkan daun. Nah daun itu kan punya tulang daun, jadi ya biar serasi ditambahkan garis-garis. Jadi harus bertemu di satu titik.

\section{Menemukan Konsep Kesebangunan dan Kekongruenan pada Batik Kangkung Setingkes}

Konsep kesebangunan pada ornamen batik tulis Kangkung Setingkes, diantaranya pada bagian bunga, daun, batang, serta kelopak bunga. Ornamenornamen tersebut dibuat dengan ukuran yang beragam ada yang berukuran kecil, sedang, dan besar namun dengan bentuk yang sama. Hal ini dapat dilihat pada Gambar 4.
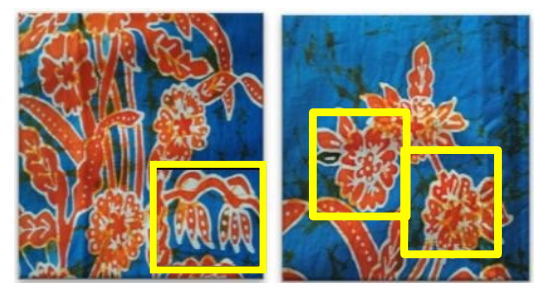

Gambar 4. Ilustrasi Konsep Kesebangunan dan Kekongruenan

\section{Menemukan Konsep Transformasi Geometri pada Batik Kangkung Setingkes}


Konsep translasi nampak pada ornamen batik motif Kangkung Setingkes dan Buah Naga dimana ornamen tersebut mengalami pergeseran posisi dengan jarak tertentu yang dapat dilihat pada Gambar 5. Konsep rotasi muncul akibat perputaran antar daun dengan salah satu kelopak bunga sebagai sumbu putarnya dengan sudut kurang dari $90^{\circ}$ yang dapat dilihat pada Gambar 6. Konsep refleksi muncul akibat teknik menjiplak dengan posisi kertas terbalik sehingga menghasilkan motif seperti dicerminkan yang dapat dilihat pada Gambar 7, dan konsep dilatasi muncul pada bagian daun yang menjuntai ke bawah dengan perbesaran tertentu. Ini dapat dilihat pada Gambar 8. Pertanyaan dan jawaban narasumber mengenai aktivitas pembuatan pola translasi sebagai berikut.

P:7007 : Bagian bunganya kan digeser ya Bu? Dipindahkan dari sisi ke sisi yang lain? Apa ada jaraknya $\mathrm{Bu}$ ?

N:7007 : Iya ada mbak, tapi ga diukur. Cuma dikira-kira saja biar gak terlihat menumpuk. Kalau motif yang besar ini mbak melihat dari kebutuhan penjahitnya. Misal sisi yang ini (sambil menunjuk Batik Kangkung Setingkes) dibutuhkan untuk bagian lengan, bagian depan, dan belakang. Jadi ada posisi yang terbalik tetapi jaraknya tetap sama.

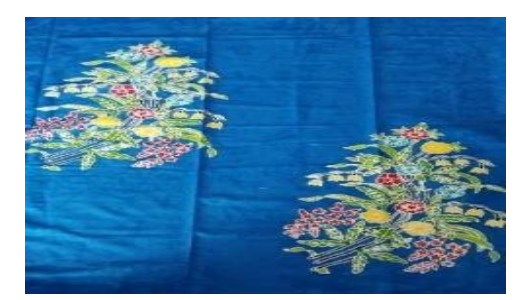

Gambar 5. Ilustrasi Konsep Translasi

Pertanyaan dan jawaban narasumber mengenai aktivitas pembuatan pola rotasi sebagai berikut.

P:7008 : $\quad$ Bu, daunnya kan memiliki 3 helai daun. Nah ini bisa sama, apa teknik Ibu untuk membuatnya sehingga nampak sama?

N:7008 : Sudah terbiasa mbak, saya ngikuti pola yang sudah dibuat sebelumnya.

P:7009 : Berapa jarak yang Ibu berikan?

N:7009 : Ga ada sih mbak, pokoknya itu bercabang tiga sama kayak yang lain.

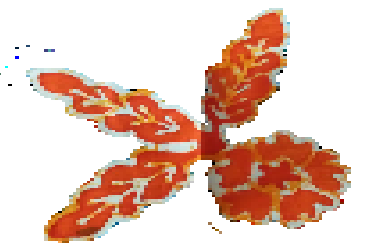

Gambar 6. Ilustrasi Konsep Rotasi 
Pertanyaan dan jawaban narasumber mengenai aktivitas pembuatan pola refleksi sebagai berikut.

P:7010 : Bu, ini ada gambar Kangkung Setingkes utuh dengan posisi terbalik. Bagaimana cara Ibu membuatnya?

N:7010 : Mengikuti pola mbak. Awalnya kan gambar di kertas, terus di blat ke kainnya. Kalau posisinya terbalik gini bisa dilakukan dengan melipat kain dulu mbak. Atau nggak, pola yang ada dikertas itu ditebeli dulu baru diblatkan ke kainnya. Caranya sama aja mbak.

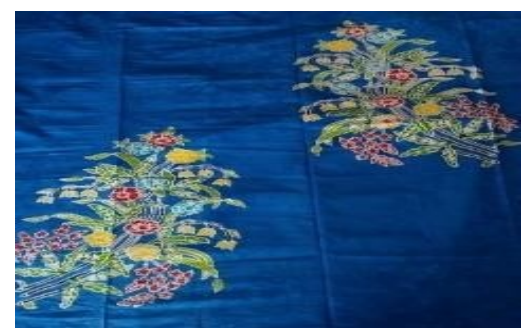

Gambar 7. Ilustrasi Konsep Refleksi

Pertanyaan dan jawaban narasumber mengenai aktivitas pembuatan pola dilatasi sebagai berikut.

P:7012 : Bu, yang bagian ini kenapa ukurannya gak sama?

N:7012 : Iya mbak, buat variasi. Anggap saja kalau misalkan ini Kangkung asli, pasti kan nanti mengalami pertumbuhan jadinya beberapa bagiannya beda ukurannya, kalau dibatik ya begini ada ukuran yang berbeda-beda tapi bentuknya kita usahakan buat sama.

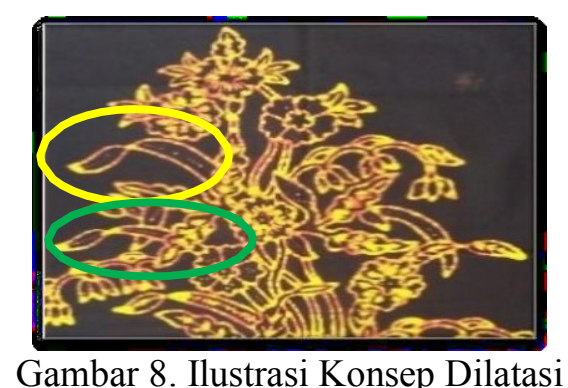

Batik adalah suatu cara penerapan corak di atas kain melalui proses celup rintang warna dengan malam sebagai medium perintangnya [7]. Batik Kangkung Setingkes adalah salah satu motif batik asli dari Banyuwangi. Proses pembuatan batik, jika dihubungkan dengan matematika memuat aktivitas menghitung, mengukur, dan membilang sedangkan pada motif batik Kangkung Setingkes jika dihubungkan dengan matematika merupakan salah satu motif yang berbentuk geometris. Ciri khas batik ini bergambar sayuran kangkung yang diikat oleh 
sebuah tali yang memiliki makna pentingnya menumbuhkan kerukunan dalam kehidupan keluarga.

Motif batik Kangkung Setingkes memiliki konsep matematika dalam bentuk maupun proses pembuatannya. Oleh karena itu, konsep matematika pada proses pembuatan batik disebut etnomatematika. Etnomatematika adalah suatu pendekatan yang mengaitkan antara matematika dengan konsep-konsep kebudayaan tertentu yang di dalamnya mencakup aktivitas-aktivitas matematika yang digambarkan pada konteks budaya [3].

Aktivitas menghitung muncul saat pembatik menentukan banyaknya motif Kangkung Setingkes pada satu lembar kain, menghitung kebutuhan malam, menghitung perbandingan pewarna, serta menghitung kebutuhan waterglass. Berdasarkan hal tersebut, etnomatematika yang termuat pada aktivitas menghitung adalah operasi hitung dan perbandingan senilai.

Aktivitas mengukur muncul saat pembatik mengukur kebutuhan air pada proses nglorod. Ukuran air yang dibutuhkan yaitu setengah dari wadah yang digunakan. Berdasarkan hasil penelitian, wadah yang digunakan untuk proses penglorodan tergantung pada jumlah kain, apabila jumlah kain yang akan diproduksi banyak maka wadah yang digunakan adalah tong sedangkan apabila kain dalam jumlah sedikit maka wadah yang digunakan cukup panci kecil. Demikian pula kebutuhan air akan semakin meningkat jika kain yang diproduksi dalam jumlah banyak. Berdasarkan hal tersebut, etnomatematika yang termuat pada aktivitas mengukur adalah perbandingan senilai.

Aktivitas membilang muncul ketika pembatik menyebutkan suatu bilangan dan satuan untuk ukuran tertentu. Aktivitas membilang berkaitan dengan penyebutan satu toples, satu gayung, lima belas menit, dan tiga jam. Satuan yang sering digunakan adalah centimeter (cm), meter (m), liter (1), yard, ons (hg), dan gram (gr).

Konsep geometri meliputi unsur titik, garis, sudut, kesebangunan, kekongruenan, dan transformasi geometri. Unsur titik dan garis, keduanya merupakan isian yang terletak pada bagian kelopak bunga serta daun. Pemberian isian bertujuan untuk memperindah motif batik Kangkung Setingkes agar tidak 
ada ornamen yang kosong. Konsep sudut muncul pada pembuatan pola batik, yakni terdapat dua sinar garis yang bertemu pada satu titik pangkal yang sama dengan tujuan membentuk tulang daun. Konsep kesebangunan muncul pada pola batik bagian bunga dan daun yang melengkung. Beragamnya ukuran ornamen pada Batik Kangkung Setingkes dibuat dengan tujuan menambah keserasian antar pola satu dengan yang lain. Konsep kekongruenan nampak pada ornamen yang mengalami translasi.

Konsep transformasi geometri yakni translasi muncul akibat pergeseran antar motif Kangkung Setingkes dan Buah Naga dengan satuan jarak tertentu, rotasi muncul akibat perputaran antar daun dengan salah satu kelopak bunga sebagai sumbu putarnya, refleksi muncul akibat teknik menjiplak dengan posisi kertas terbalik sehingga menghasilkan motif seperti dicerminkan, dan dilatasi muncul pada bagain daun yang menjuntai ke bawah dengan perbesaran tertentu.

Lembar Kerja Siswa yang dihasilkan merupakan hasil penelitian pada pembuatan batik tulis Kangkung Setingkes. Melalui LKS siswa dibimbing untuk memecahkan persoalan yang diberikan dengan tujuan siswa mampu membangun atau mengkonstruksi sendiri pengetahuannya [9]. Adapun desain LKS ini berisi kompetensi inti, kompetensi dasar, indikator pencapaian pembelajaran, petunjuk pengerjaan, deskripsi terkait alat dan bahan membatik, deskripsi terkait batik Kangkung Setingkes, ringkasan materi terkait perbandingan, serta ringkasan materi terkait tranformasi geometri.

Berdasarkan analisis data yang telah dilakukan, diperoleh informasi bahwa pada proses pembuatan batik memiliki unsur matematika. sehingga diperoleh informasi bahwa etnomatematika yang ditemukan pada proses pembuatan batik adalah titik, garis, sudut, kesebangunan, kekongruenan, dan transformasi geometri (translasi, rotasi, refleksi, dilatasi).

\section{KESIMPULAN}

Berdasarkan hasil analisis dan pembahasan, dapat disimpulkan bahwa pada proses pembuatan batik Kangkung Setingkes di Perusahaan Tatsaka Cluring Banyuwangi terdapat konsep matematika. Konsep matematika yang dimaksud adalah konsep aljabar dan konsep geometri. Konsep aljabar meliputi aktivitas 
menghitung, mengukur, dan membilang. Konsep geometri meliputi unsur titik, garis, sudut, kesebangunan, kekongruenan, dan transformasi geometri (translasi, rotasi, refleksi, dilatasi). Hasil dari penelitian ini dijadikan sebagai bahan Lembar Kerja Siswa yang sesuai dengan kurikulum 2013. LKS etnomatematika materi per bandingan dapat dilihat pada https://drive.google.com/file/d/19n7o33kTd5Jh5XxSGKyIiBv_ENSOtpN0/view? usp=drivesdk dan LKS materi transformasi geometri d apat dilihat pada https://drive.google.com/file/d/19rtHbxqqBOWj5O8Kvxj68fC1N QKChFo/view? usp $=$ drivesdk.

Adapun saran untuk penelitian selanjutnya adalah menggali lebih dalam mengenai pembuatan batik untuk mengetahui lebih lengkap terkait konsep matematika yang ada didalamnya, menentukan waktu yang tepat untuk penelitian agar seluruh proses pembuatan batik dapat teramati dengan baik, serta memberikan pertanyaan yang lebih detail sehingga dapat memperoleh data yang sesuai dengan fokus kajian dan tujuan penelitian.

\section{DAFTAR PUSTAKA}

[1] S. Haji, "Pengaruh Pembelajaran Kontekstual Terhadap Kemampuan Komunikasi Matematika Siswa SMP Kota Bengkulu," Jurnal Exacta, vol. 10, no. 2, pp. 115-118, 2012.

[2] A. Fauzi and H. Setiawan, "Etnomatematika: Konsep Geometri Pada Kerajinan Tradisional Sasak Dalam Pembelajaran Matematika Di Sekolah Dasar," Jurnal Pendidikan dan Ilmu Pengetahuan, vol. 20, no.2, pp. 119$128,2020$.

[3] E. P. Astuti, R. Y. Purwoko, and M. W. Sintiya, "Bentuk Etnomatematika Pada Batik Adipurwo Dalam Pembelajaran Pola Bilangan," Journal of Mathematics Science and Education, vol. 1, no. 2, pp. 1-16, 2019.

[4] S. Andriani and I. Septiani, "Etnomatematika Motif Ceplokan Batik Yogyakarta Dalam Peningkatan Pemahaman Konsep Matematika Siswa," Jurnal Ilmiah Pendidikan Matematika, vol. 8, no. 1, pp. 81-92, 2020.

[5] Melisa, W. Widada, and Zamzaili, "Pembelajaran Matematika Realistik Berbasis Etnomatematika Bengkulu untuk Meningkatkan Kognisi Matematis," Jurnal Pendidikan Matematika Raflesia, vol. 4, no. 2, pp. 103$110,2019$.

[6] A. D. I. Christanti, F. Y. Sari, and E. Pramita, "Etnomatematika Pada Batik Kawung Yogyakarta Dalam Transformasi Geometri," Seminar Nasional Pendidikan Matematika, vol. 1, no. 1, pp.435-444, 2020.

[7] A. B. Prizilla and A. Sachari, "Teknik Klowong Dalam Upaya Pengembangan Model Pewarisan Tradisi Membatik Warga Rifa'iyah Di Desa 
Kalipucang Wetan, Jawa Tengah,” Jurnal Visualita, vol.7, no.2, pp.1-12, 2019.

[8] D. Friansah and M. Luthfiana, "Desain Lembar Kerja Siswa Materi Sistem Persamaan Dua Variabel Berorientasi Etnomatematika," Jurnal Pendidikan Matematika, vol.1, no.2, pp.83-92, 2018.

[9] N. P. Seniwati and I. W. Nayun, "Efektivitas Metode Inkuiri Terbimbing Berbantuan Lks Untuk Meningkatkan Prestasi Belajar Matematika," Suluh Pendidikan, vol. 16, no.1, pp. 41-49, 2018.

[10] Prabawati, Herman, and Turmudi, "Pengembangan Lembar Kerja Siswa Berbasis Masalah dengan Strategi Heuristic untuk Meningkatkan Kemampuan Literasi Matematis," Jurnal Pendidikan Matematika, vol. 8, no. 1, pp.37-48, 2019. 